\title{
Callose Deposition: A Multifaceted Plant Defense Response
}

\author{
Estrella Luna, ${ }^{1}$ Victoria Pastor, ${ }^{3}$ Jérôme Robert, ${ }^{2}$ Victor Flors, ${ }^{3}$ Brigitte Mauch-Mani, ${ }^{2}$ and Jurriaan Ton ${ }^{1}$ \\ ${ }^{1}$ Department of Biological Chemistry, Rothamsted Research, Harpenden AL5 2JQ U.K.; ${ }^{2}$ Institute of Botany, University \\ of Neuchâtel, Neuchâtel, CH-2009 Switzerland; ${ }^{3}$ Plant Physiology Section, CAMN Department, University of Jaume I, \\ Castellón, 12071 Spain
}

Submitted 2 July 2010. Accepted 8 October 2010.

\begin{abstract}
Callose deposition in Arabidopsis has emerged as a popular model system to quantify activity of plant immunity. However, there has been a noticeable rise in contradicting reports about the regulation of pathogen-induced callose. To address this controversy, we have examined the robustness of callose deposition under different growth conditions and in response to two different pathogen-associated molecular patterns, the flagellin epitope Flg22 and the polysaccharide chitosan. Based on a commonly used hydroponic culture system, we found that variations in growth conditions have a major impact on the plant's overall capacity to deposit callose. This environmental variability correlated with levels of hydrogen peroxide $\left(\mathrm{H}_{2} \mathrm{O}_{2}\right)$ production. Depending on the growth conditions, pretreatment with abscissic acid stimulated or repressed callose deposition. Despite a similar effect of growth conditions on Flg22- and chitosaninduced callose, both responses showed differences in timing, tissue responsiveness, and colocalization with $\mathrm{H}_{2} \mathrm{O}_{2}$. Furthermore, mutant analysis revealed that FIg22- and chitosan-induced callose differ in the requirement for the NADPH oxidase RBOHD, the glucosinolate regulatory enzymes VTC1 and PEN2, and the callose synthase PMR4. Our study demonstrates that callose is a multifaceted defense response that is controlled by distinct signaling pathways, depending on the environmental conditions and the challenging pathogen-associated molecular pattern.
\end{abstract}

Plants protect themselves against pathogens by using a variety of chemical and physical defense mechanisms. Callose-containing cell-wall appositions, called papillae, are effective barriers that are induced at the sites of attack during the relatively early stages of pathogen invasion. Callose is an amorphous, high-molecular weight $\beta$-(1,3)-glucan polymer that serves as a matrix in which antimicrobial compounds can be deposited, thereby providing focused delivery of chemical defenses at the cellular sites of attack. Callose deposition is typically triggered by conserved pathogen-associated molecular patterns (PAMPs) (Brown et al. 1998; Gomez-Gomez et al. 1999a). Examples of bacterial PAMPs are the 22-amino acid sequence of the con-

Estrella Luna and Victoria Pastor contributed equally to the work

Corresponding authors: Victor Flors; Telephone: +34-964729417; E-mail: flors@uji.es; Brigitte Mauch-Mani; Telephone: +41-327182205; E-mail: brigitte.mauch@unine.ch; Jurriaan Ton; Telepone: +44-1582763133; Email: jurriaan.ton@bbsrc.ac.uk

* The $\boldsymbol{e}$-Xtra logo stands for "electronic extra" and indicates that three supplementary figures and a supplementary table are published online. served N-terminal part of flagellin (Gomez-Gomez and Boller 2000) and the bacterial elongation factor EF-Tu (Elf18) (Kunze et al. 2004). Chitin, a $\beta$-(1,4)-linked polymer of $N$-acetylglucosamine, and chitosan, a randomly distributed $\beta-(1,4)-$ linked polymer of D-glucosamide and acetylglucosamine, are examples of potent callose-inducing PAMPs from fungal cell walls (Iritri and Faoro 2009). Apart from PAMPs, endogenous elicitors from pathogen- or herbivore-damaged plant tissues can activate callose depositions as well. Well-known examples of damage-associated patterns (DAMP) are oligogalacturonides (OG) (Ridley et al. 2001).

The signaling pathways controlling PAMP-triggered immunity (PTI) are under the control of pathogen recognition receptors (PRR). Activity of the downstream pathways is marked by common signaling events, such as anion fluxes, protein phosphorylation cascades, accumulation of reactive oxygen species (ROS), and defense gene induction (Boller and Felix 2009; Jeworutzki et al. 2010; Nicaise et al. 2009). Recently, PAMPor DAMP-induced callose deposition in cotyledons or leaves of Arabidopsis has emerged as a popular marker response to study the signaling pathways controlling PTI or the suppression of these pathways by virulence-promoting pathogen effectors (Table 1). The advantage of this model system is that it allows for rapid and relatively simple screening of PTI activity. The model system has been used to demonstrate that reactive oxygen species (ROS) act as positive signals in Flg22- and OG-induced callose (Galletti et al. 2008; Zhang et al. 2007), and recently, it was found that the RNA interference regulatory protein Argonaute1 generates various miRNA signals that stimulate or repress Flg22-induced callose (Li et al. 2010). Furthermore, Flg22-induced callose in Arabidopsis has been demonstrated to require intact biosynthesis of 4-methoxylated indole glucosinolates (Clay et al. 2009), suggesting that these secondary metabolites or break-down products thereof play a crucial role in the regulation of callose.

The timing and intensity of pathogen-induced callose can be influenced by environmental signals. For example, plants that are locally subjected to pathogen attack express systemic acquired resistance, which is associated with augmented levels of callose upon secondary pathogen inoculation (Kohler et al. 2002). Furthermore, resistance-inducing chemicals can augment depositions of pathogen-inducible callose. Well-known examples of such priming agents are the salicylic acid (SA) analog benzo(1,2,3) thiadiazole-7-carbothioic acid $S$-methyl ester (Kohler et al. 2002), and the nonprotein amino acid $\beta$-amino butyric acid (BABA) (Ton and Mauch-Mani 2004; Zimmerli et al. 2000). We have previously demonstrated that BABA-induced priming of callose requires an intact abscissic acid (ABA)-dependent pathway in Arabidopsis. Since ABA regulates plant 
adaptation to abiotic stress, these findings suggest that pathogen-induced callose is coregulated by abiotic stress signals (Flors et al. 2005; Mauch-Mani and Mauch 2005). Indeed, in recent years, ABA has emerged as a multifaceted modulator of disease resistance (Asselbergh et al. 2008; Ton et al. 2009).

The role of ABA in disease resistance depends on a multitude of factors, such as the attacking pathogen, its specific way of gaining entry into the host, the timing of the defense response, and the type of plant tissue that is under attack. In general, ABA exerts a positive influence on early-acting defenses, such as stomatal closure, but a negative influence on later-acting defense mechanisms that are under the control of plant hormones SA and jasmonic acid (Ton et al. 2009). Nevertheless, this trend does not explain the controversial function of ABA in pathogen-induced callose. It was recently reported that ABA suppresses callose deposition in Arabidopsis cotyledons after treatment with the bacterial PAMP flagellin (Clay et al. 2009), which is supported by earlier findings that callose induced by Pseudomonas syringae pv. tomato is suppressed by ABA (de Torres-Zabala et al. 2007). Contrary to these findings, other groups have demonstrated a positive influence of ABA on callose deposition in response to infection by different fungal and oomycete pathogens (Asselbergh et al. 2008; Flors et al. 2005; Ton et al. 2009). In fact, a DNA/RNA nuclease was recently reported to act as a critical regulator of ABA-dependent stimulation of callose deposition during Botrytis cinerea infection (You et al. 2010).

In this study, we have evaluated the robustness of a widely used hydroponic Arabidopsis system to quantify PAMPinduced callose. Our results demonstrate that variations in abiotic growth conditions have a major impact on the plant's capacity to deposit callose in this system, which correlate with levels of $\mathrm{H}_{2} \mathrm{O}_{2}$ in the tissue. Moreover, the impact of ABA on callose deposition varied from repressive to stimulatory, depending on the growth conditions. We furthermore demonstrate that the pathways controlling callose differ according to the challenging PAMP, illustrating that pathogen-induced callose is a multifaceted defense response that is regulated by multiple signals rather than one, conserved signaling pathway.

\section{RESULTS}

\section{Flg22- and chitosan-induced callose} in hydroponically grown Arabidopsis.

To make a direct comparison between Flg22- and chitosaninduced callose, Arabidopsis seedlings were grown at an irradiance of $150 \mu \mathrm{E} \mathrm{m}^{-2} \mathrm{~s}^{-1}$ in hydroponic Murashige and Skoog medium containing $1 \%$ sucrose without Gamborg vitamins. At $24 \mathrm{~h}$ after application of $1 \mu \mathrm{M}$ Flg22 or $0.01 \%$ chitosan (wt/vol), cotyledons were collected, stained with aniline blue, and examined by UV epifluoresence microscopy. As is illustrated in Figure 1A, both PAMP treatments caused a noticeable increase in the number of callose depositions compared with the mock treatment. However, the size of individual callose depositions in chitosan-treated plants appeared larger than those from Flg22-treated plants. To enumerate these differences, callose was quantified from digital photographs and was


$\square$ mock

Flg22

Chitosan

Fig. 1. Phenotype of Flg22- and chitosan-induced callose. A, Morphologic differences between callose depositions in cotyledons of 9-day-old Arabidopsis seedlings (Col-0) at $24 \mathrm{~h}$ after mock treatment, $1 \mu \mathrm{M}$ Flg22 or $0.01 \%$ chitosan. Photographs of aniline blue-stained cotyledons under UV epifluorescence show representative differences in callose depositions between treatments. Seedlings were cultivated at $150 \mu \mathrm{E} \mathrm{m}^{-2} \mathrm{~s}^{-1}$ of light in liquid Murashige Skoog medium containing 1\% sucrose without Gamborg vitamins. B, Relative callose intensities were quantified as the number of fluorescent callose-corresponding pixels relative to the total number of pixels covering plant material. Values represent means ( \pm standard error of the mean (SEM); $n>20$ ), standardized to the mean callose intensity in mock-treated seedlings. C, Relative numbers of callose depositions were quantified as the number of individual depositions per unit of cotyledon surface. Values represent means ( \pm SEM; $n>20$ ), standardized to the mean number in mock-treated seedlings. Different letters indicate statistically significant differences between treatments (Fisher's least significant differences test; $\alpha=0.05$ ).

Table 1. Recent publications that have used PAMP-induced callose deposition in Arabidopsis as a marker for PTI activity ${ }^{\mathrm{a}}$

\begin{tabular}{|c|c|c|c|}
\hline Experimental system & PAMP & Signaling process & Reference \\
\hline Application to hydroponically grown seedlings & $\begin{array}{l}\text { Flg22, chitin, } \\
\text { peptidoglycan }\end{array}$ & $\begin{array}{l}\text { Induction of PTI and effector-triggered } \\
\text { suppression of PTI in roots. }\end{array}$ & Millet et al. 2010 \\
\hline Infiltration in leaves & Flg22 & $\begin{array}{l}\text { Regulation of defense gene expression by } \\
\text { miRNAs }\end{array}$ & Li et al. 2010 \\
\hline Application to hydroponically grown seedlings & Flg22, Elf18 & Poly(ADP-ribosyl)ation & Adams-Phillips et al. 2010 \\
\hline Application to hydroponically grown seedlings & Flg22, Elf18 & PRR quality control in the ER & Lu et al. 2009 \\
\hline Application to hydroponically grown seedlings & Flg22, Elf18 & PRR quality control in the ER & Saijo et al. 2009 \\
\hline Infiltration in leaves & Flg22 & PAMP activity by bacterial DNA & Yakushiji et al. 2009 \\
\hline Infiltration in leaves & Flg22 & Induction of salicylic acid accumulation & Wang et al. 2009 \\
\hline Application to hydroponically grown seedlings & Flg22 & Induction of glucosinolate metabolites & Clay et al. 2009 \\
\hline Infiltration in leaves & Oligogalacturonides & Reactive oxygen species signaling & Galletti et al. 2008 \\
\hline Infiltration in leaves & $\mathrm{Flg} 22$ & $\begin{array}{l}\text { Protein phosphorylation and reactive oxygen } \\
\text { species signaling }\end{array}$ & Zhang et al. 2007 \\
\hline Infiltration in leaves & Flg22 & $\begin{array}{l}\text { Effector-triggered suppression of PTI via } \\
\text { ADP ribosylation. }\end{array}$ & Fu et al. 2007 \\
\hline Application to hydroponically grown seedlings & Flg22 & Activity of the FLS2 receptor & Dunning et al. 2007 \\
\hline
\end{tabular}

${ }^{\text {a }}$ PAMP = pathogen-associated molecular pattern; PTI = PAMP-triggered immunity; PRR = pathogen recognition receptors; ER = endoplasmic reticulum. 
expressed as the relative number of callose-corresponding pixels (callose intensity) or the relative number of callose depositions. Whereas the number of depositions did not differ between Flg22- and chitosan-treated seedlings, callose intensity was significantly higher in chitosan-treated seedlings than in Flg22-treated seedlings (Fig. 1B). Hence, $0.01 \%$ chitosan triggers higher amounts of callose per deposition than $1 \mu \mathrm{M}$ Flg22. Further dose-response analysis revealed that this difference in callose morphology was also apparent at other concentrations of the applied PAMPs (Supplementary Fig. S1; data not shown). Since $1 \mu \mathrm{M}$ flg 22 and $0.01 \%$ chitosan yielded the most consistent levels of callose elicitation between independent experiments, subsequent experiments were carried out with these doses, unless stated otherwise.

\section{Impact of growth conditions on callose deposition.}

Levels of Flg22- and chitosan-induced callose in hydroponically grown Arabidopsis were measured under different environmental growth conditions. To minimize possible bias from unaccounted environmental conditions, results are presented from experiments with consistent outcomes in three different laboratories (Supplementary Table S1). Data presented in the figures show average values from pooled datasets. Increasing concentrations of sucrose in the growth medium had a general suppressive effect on callose deposition (Fig. 2A). Although 1 and $2.5 \%$ sucrose did not have a profound impact on the level of basal callose deposition in mock-treated seedlings, addition of $5 \%$ sucrose to the growth medium suppressed basal callose deposition by sixfold compared with plants at $0 \%$ sucrose. Moreover, Flg22-induced callose was significantly repressed at 2.5 and $5 \%$ sucrose, whereas chitosan-induced callose was already repressed at $1 \%$ sucrose in comparison to $0 \%$ sucrose. Hence, sucrose represses basal and PAMP-induced callose. Next, we investigated the effects of light on callose deposition. Seedlings grown at the relatively low light intensity of $75 \mu \mathrm{E}$ $\mathrm{m}^{-2} \mathrm{~s}^{-1}$ deposited significantly lower levels of basal and Flg22induced callose than seedlings grown at $150 \mu \mathrm{E} \mathrm{m}^{-2} \mathrm{~s}^{-1}$ (Fig. 2B), suggesting that light boosts basal and Flg22-induced callose. Differences in light intensity did not statistically affect quantities of chitosan-induced callose (Fig. 2B). Finally, we examined the impact of vitamins in the growth medium. Gamborg vitamins are commonly used to supplement hydroponic plant culture media. Notably, this supplement consists of a mixture of potent antioxidant vitamins, such as myo-inositol,
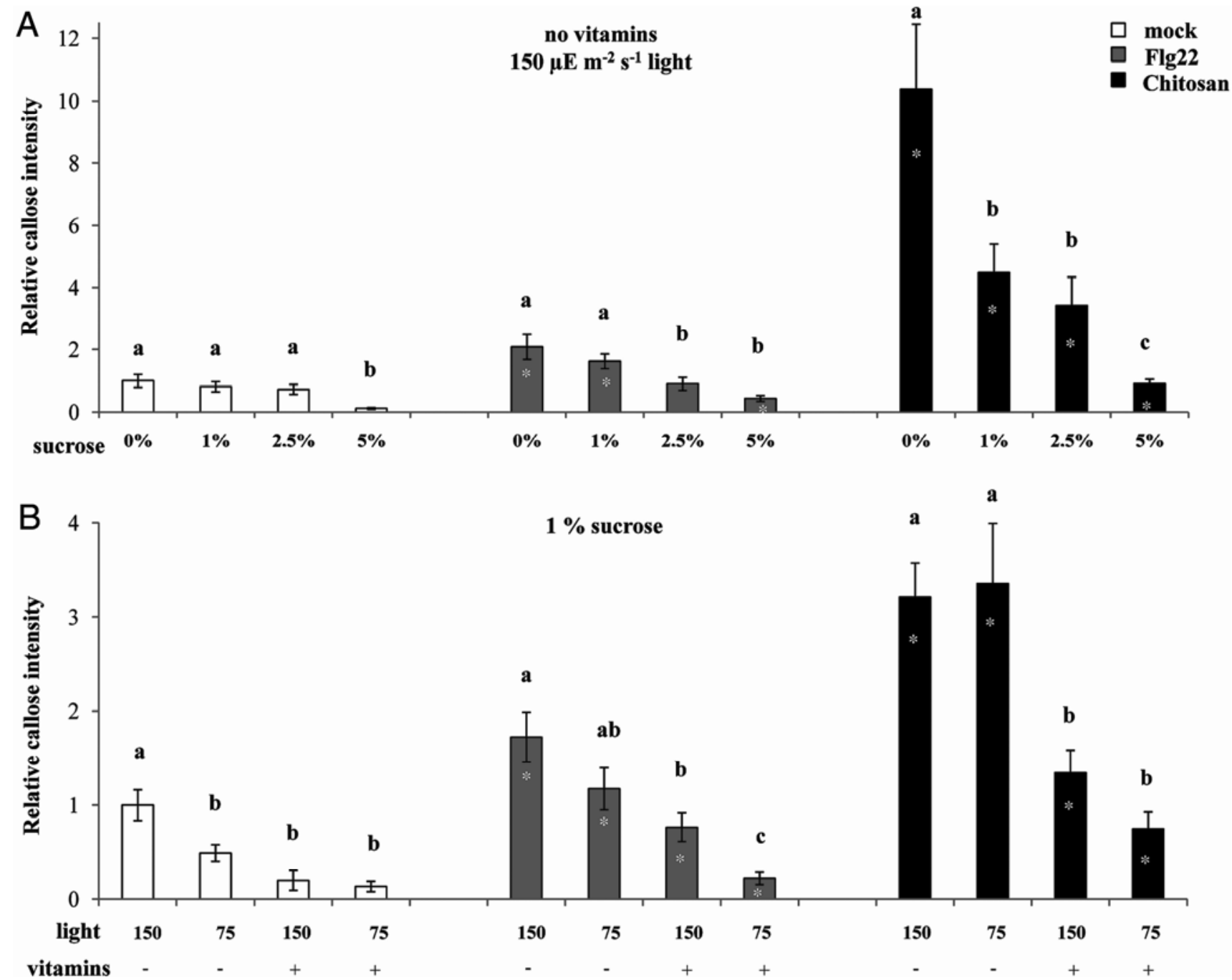

Fig. 2. Impact of growth conditions on callose deposition in cotyledons of 9-day-old Arabidopsis seedlings (Col-0). Data shown are average values of relative callose intensities ( \pm standard error of the mean; $n>20$ ) at $24 \mathrm{~h}$ after treatment with $1 \mu \mathrm{M} \mathrm{Flg} 22$ or $0.01 \%$ chitosan. Values were standardized to the callose intensity in mock-treated seedlings at $150 \mu \mathrm{E} \mathrm{m}^{-2} \mathrm{~s}^{-1}$ of light, $1 \%$ sucrose, and without Gamborg vitamins. Different letters indicate statistically significant differences between growth conditions (Fisher's least significant differences test; $\alpha=0.05$ ). Asterisks indicate statistically significant differences between pathogen-associated molecular pattern treatments and corresponding controls at similar growth conditions (Student's $t$-test; $\alpha=0.05$ ). A, Impact of sucrose on callose deposition. B, Impact of light and Gamborg vitamins on callose deposition. 
thiamine, and nicotinic acid (Gamborg et al. 1968). Cultivation of seedlings in medium with Gamborg vitamins drastically suppressed basal, Flg22-, and chitosan-induced callose (Fig. 2B), suggesting a positive role of ROS in callose regulation. The relative numbers of callose depositions displayed a similar responsiveness to the variable growth conditions as the relative callose intensities (data not shown). Overall, these results demonstrate that environmental growth conditions in hydroponically grown Arabidopsis have a profound impact on the regulation of callose deposition.

\section{Impact of growth conditions on $\mathrm{H}_{2} \mathrm{O}_{2}$ accumulation.}

Because antioxidant Gamborg vitamins suppressed basal and PAMP-induced callose (Fig. 2B), we examined to what extent this variation is related to endogenous $\mathrm{H}_{2} \mathrm{O}_{2}$ levels. To this end, seedlings were grown under different growth conditions and were fixed in acidic 3,3-diaminobenzidine (DAB) staining solution $(\mathrm{pH}<3)$ at $24 \mathrm{~h}$ after PAMP treatment. $\mathrm{H}_{2} \mathrm{O}_{2}$ levels were quantified digitally by the relative number of darkbrown pixels after $24 \mathrm{~h}$ of staining. Callose-suppressive growth conditions, such as low light $\left(75 \mu \mathrm{E} \mathrm{m} \mathrm{m}^{-2} \mathrm{~s}^{-1}\right), 5 \%$ sucrose, or the presence of Gamborg vitamins, suppressed basal and PAMPinduced $\mathrm{H}_{2} \mathrm{O}_{2}$ (Fig. 3). Conversely, callose-promoting growth conditions, such as high light intensity $\left(150 \mu \mathrm{E} \mathrm{m}^{-2} \mathrm{~s}^{-1}\right), 1 \%$ sucrose, or lack of vitamins (Fig. 2), allowed significantly higher levels of basal and PAMP-induced $\mathrm{H}_{2} \mathrm{O}_{2}$ (Fig. 3). Hence, the observed variation in callose deposition under different growth conditions correlates with levels of $\mathrm{H}_{2} \mathrm{O}_{2}$ accumulation in the tissue.

\section{The impact of ABA on callose deposition varies according} to the growth conditions.

The role of $\mathrm{ABA}$ as a regulatory hormone in disease resistance has been studied extensively (Asselbergh et al. 2008; Mauch-Mani and Mauch 2005; Ton et al. 2009). Nevertheless, the role of this plant hormone in regulation of pathogeninduced callose remains controversial. To examine how closely this controversy is related to influences by abiotic growth conditions, we examined the effects of ABA application on callose under different conditions. At low light intensity $\left(75 \mu \mathrm{E} \mathrm{m}^{-2} \mathrm{~s}^{-1}\right)$,

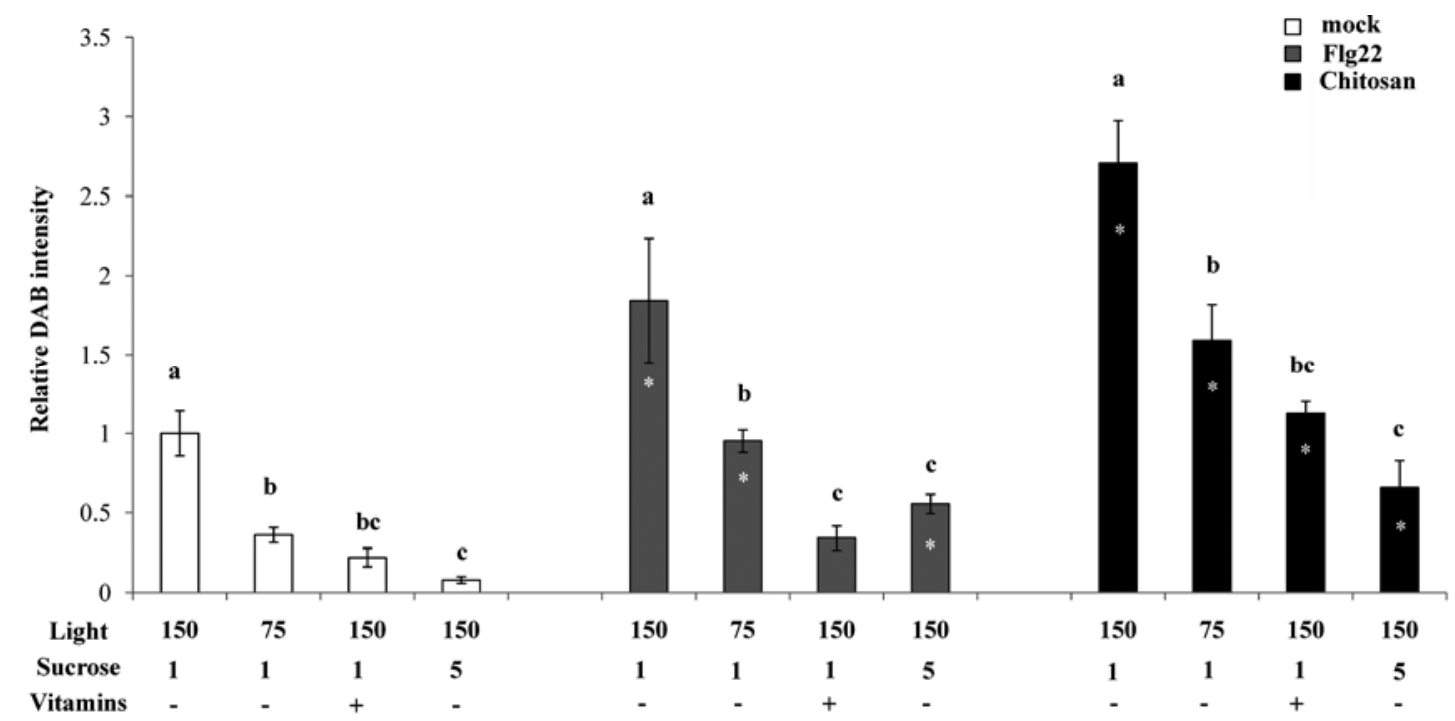

Fig. 3. Impact of growth conditions on $\mathrm{H}_{2} \mathrm{O}_{2}$ accumulation in cotyledons of 9-day-old Arabidopsis seedlings. Shown are average values of relative 3,3diaminobenzidine (DAB) staining intensities ( \pm standard error of the mean; $n>15$ ) at $24 \mathrm{~h}$ after treatment with $1 \mu \mathrm{M}$ Flg 22 or $0.01 \%$ chitosan. Values were standardized to the DAB intensity in mock-treated seedlings at $150 \mu \mathrm{E} \mathrm{m}^{-2} \mathrm{~s}^{-1}$ of light, $1 \%$ sucrose, and without Gamborg vitamins. Different letters indicate statistically significant differences between growth conditions (Fisher's least significant differences test; $\alpha=0.05$ ). Asterisks indicate statistically significant differences between pathogen-associated molecular pattern treatments and corresponding controls at similar growth conditions (Student's $t$-test; $\alpha=0.05$ ).
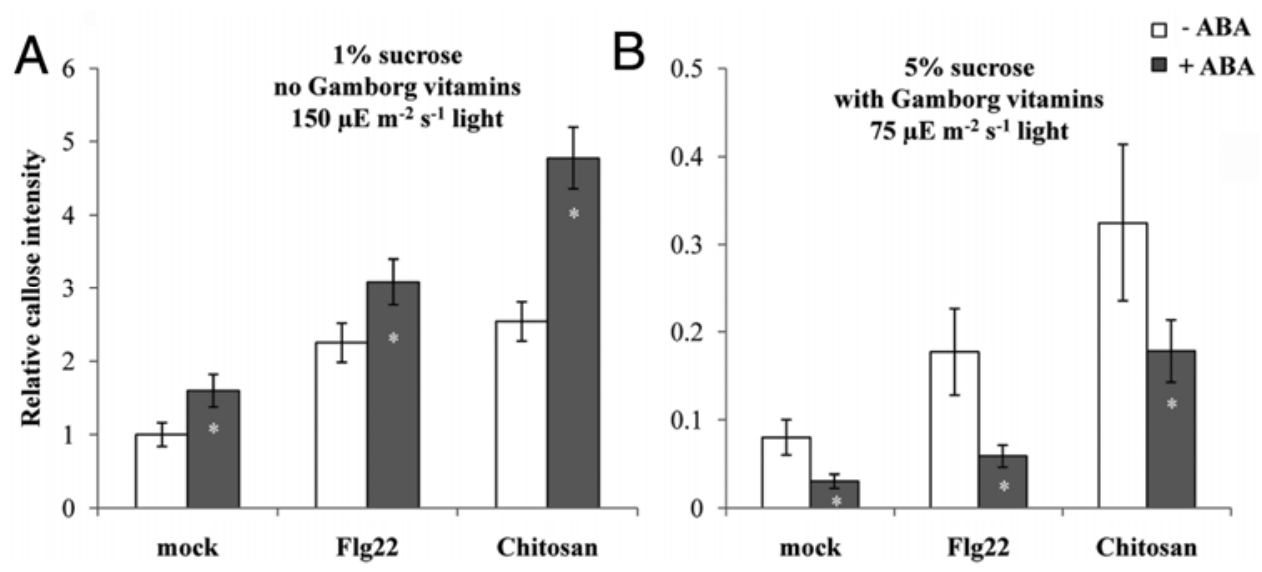

Fig. 4. Opposite impacts of abscissic acid (ABA) on callose deposition at two different growth conditions. Seedlings were treated with $5 \mu \mathrm{M} A B A$ at $24 \mathrm{~h}$ prior to pathogen-associated molecular pattern (PAMP) treatment. Data shown are average values of relative callose intensities ( \pm standard error of the mean; $n>20)$ at $24 \mathrm{~h}$ after PAMP treatment. Values were standardized to the callose intensity in mock-treated seedlings at $150 \mu \mathrm{E} \mathrm{m}{ }^{-2} \mathrm{~s}^{-1}$ of light, $1 \%$ sucrose, without Gamborg vitamins and ABA. Asterisks indicate statistically significant changes in response to ABA treatment (Student's $t$-test; $\alpha=0.05$ ). 
$5 \%$ sucrose, and with Gamborg vitamins, pretreatment with 5 $\mu \mathrm{M}$ ABA $24 \mathrm{~h}$ prior to PAMP application resulted in a repression of basal and PAMP-induced callose deposition (Fig. 4). Strikingly, when seedlings had been cultivated at high light intensity $\left(150 \mu \mathrm{E} \mathrm{m}^{-2} \mathrm{~s}^{-1}\right), 1 \%$ sucrose, and without vitamins, pretreatment with ABA stimulated basal and PAMP-induced callose (Fig. 4). Similarly contrasting effects were observed upon treatment with $50 \mu \mathrm{M}$ ABA (Table 2). To identify the exact growth conditions under which ABA represses or stimulates callose, we performed experiments under various combinations of light, sucrose, and vitamins. Only the combination of low light intensity $\left(75 \mu \mathrm{E} \mathrm{m}^{-2} \mathrm{~s}^{-1}\right), 5 \%$ sucrose, and Gamborg vitamins provided conditions under which ABA suppressed callose, whereas all other conditions supported mostly stimulatory effects by ABA (Table 2). In all experiments, numbers of callose depositions responded similarly to ABA as the callose intensities (data not shown). Since the combination of low light, high sucrose, and vitamins suppresses $\mathrm{H}_{2} \mathrm{O}_{2}$ accumulation (Fig. 3), we propose that the impact of ABA on callose changes from repressive to stimulatory, depending on a threshold of cellular ROS.

\section{Timing and localization of Flg22- and chitosan-induced $\mathrm{H}_{2} \mathrm{O}_{2}$ and callose.}

To further investigate the role of ROS in PAMP-induced callose, we examined the dynamics of $\mathrm{H}_{2} \mathrm{O}_{2}$ accumulation in response to $\mathrm{Flg} 22$ and chitosan in a time-series experiment. Seedlings were cultivated at callose- and $\mathrm{H}_{2} \mathrm{O}_{2}$-promoting growth conditions ( $1 \%$ sucrose, $150 \mu \mathrm{E} \mathrm{m}^{-2} \mathrm{~s}^{-1}$ of light, no vitamins) and were fixed in acidic DAB staining solution at different timepoints after PAMP induction. Both Flg22 and chitosan strongly elicited $\mathrm{H}_{2} \mathrm{O}_{2}$ production at 30 min after application (Fig. 5A). However, Flg22-induced $\mathrm{H}_{2} \mathrm{O}_{2}$ was more transient than chitosan-induced $\mathrm{H}_{2} \mathrm{O}_{2}$, which was more sustained and lasted up to $24 \mathrm{~h}$ after induction treatment. In a separate experiment, we assessed the dynamics of callose deposition under similar growth conditions. Also here, the dynamics of the callose response differed considerably between both PAMP treatments. Whereas chitosan-induced callose was already apparent at $2 \mathrm{~h}$ after treatment, Flg22-induced callose was not significantly induced until $8 \mathrm{~h}$ after treatment (Fig. 5B). Hence, Flg22- and chitosan-induced callose are preceded by $\mathrm{H}_{2} \mathrm{O}_{2}$ accumulation, but the dynamics of both PAMP responses differs between Flg22- and chitosan-treated seedlings.

To examine tissue localization of PAMP-induced $\mathrm{H}_{2} \mathrm{O}_{2}$ and callose, seedlings were double-stained with $\mathrm{DAB}$ and aniline blue and were examined by a combination of light and epifluorescence microscopy (UV). As is shown in Figure 5, chitosaninduced $\mathrm{H}_{2} \mathrm{O}_{2}$ accumulated at similar sites as chitosan-induced callose. On the other hand, no obvious colocalization between $\mathrm{H}_{2} \mathrm{O}_{2}$ and callose was observed after treatment with Flg22. This lack of colocalization may be caused by the more transient nature of Flg22-induced $\mathrm{H}_{2} \mathrm{O}_{2}$ accumulation (Fig. 6).

Next, we investigated the sensitivity by which different plant tissues deposit PAMP-induced callose in the hydroponic growth medium. Millet and associates (2010) recently reported that Flg22, chitin, and peptidoglycan trigger different patterns of callose deposition in roots of hydroponically growth Arabidopsis seedlings. Surprisingly, however, we did not find a significant increase in root callose upon treatment with Flg22, while chitosan triggered a strong and statistically significant root callose response (Fig. 7). This differential responsiveness was consistent at different concentrations of applied PAMPs (Fig. 7). Since the Flg22 receptor FLS2 has been shown to be

Table 2. Impact of pretreatment with $50 \mu \mathrm{M}$ abscissic acid (ABA) on basal and pathogen-associated molecular pattern (PAMP)-induced callose at different growth conditions

\begin{tabular}{lccccc}
\hline & & & & \multicolumn{2}{c}{ Effect of ABA pretreatment $^{\mathbf{b}}$} \\
\cline { 3 - 6 } Light intensity $^{\mathbf{a}}$ & Sucrose (\%) & Gamborg vitamins & Mock & Flg22 & Chitosan \\
\hline High light & 1 & No & + & + & + \\
Low light & 1 & No & + & + & n.s. \\
High Light & 5 & No & n.s. & + & + \\
Low light & 1 & Yes & n.s. & + & + \\
High light & 1 & Yes & - & - & + \\
Low light & 5 & Yes & + & + \\
\hline
\end{tabular}

${ }^{\mathrm{a}}$ High light $=150 \mu \mathrm{E} \mathrm{m}^{-2} \mathrm{~s}^{-1} ;$ Low light $=75 \mu \mathrm{E} \mathrm{m}^{-2} \mathrm{~s}^{-1}$.

${ }^{\mathrm{b}}$ Material for callose quantifications was collected at $24 \mathrm{~h}$ after mock or PAMP treatment ( $1 \mu \mathrm{M} \mathrm{Flg} 22$ or $0.01 \%$ chitosan). ABA was applied $24 \mathrm{~h}$ prior to mock or PAMP treatment. $+=$ potentiation of callose by ABA; $-=$ suppression of callose by ABA; n.s. = no statistically significant effect by ABA.
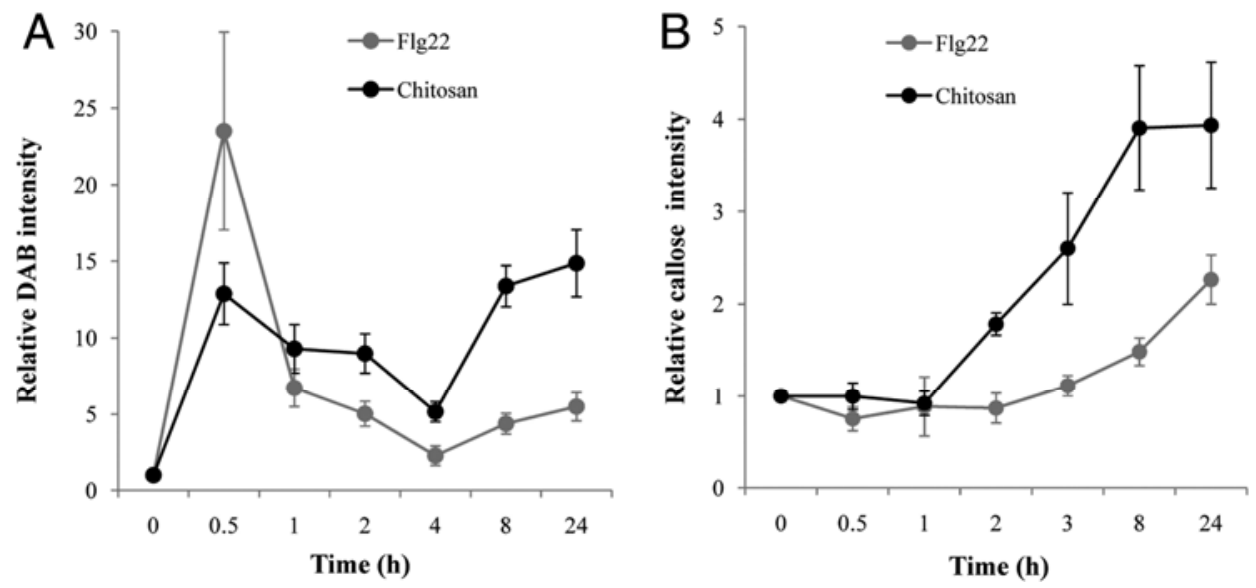

Fig. 5. Dynamics of $\mathbf{A}, \mathrm{H}_{2} \mathrm{O}_{2}$ and $\mathbf{B}$, callose deposition at different timepoints after treatment with $1 \mu \mathrm{M} \mathrm{Flg} 22$ or $0.01 \%$ chitosan. Shown are average values ( \pm standard error of the mean; $n>15$ ) of relative staining intensities standardized to mock treatments. Seedlings were grown under standard growth conditions at $150 \mu \mathrm{E} \mathrm{m}^{-2} \mathrm{~s}^{-1}$ of light, $1 \%$ sucrose, and without Gamborg vitamins. 
expressed in Arabidopsis roots (Robatzek et al. 2006), the differential callose response to Flg22 and chitosan can only be explained by dissimilarities in the downstream signaling pathways under our growth conditions. Together with differences in colocalization between Flg22- and chitosan-induced $\mathrm{H}_{2} \mathrm{O}_{2}$ and callose (Fig. 6), these results suggest that Flg22- and chitosan-induced callose are controlled by distinct pathways.

\section{Differential regulation}

of Flg22- and chitosan-induced callose.

To further investigate the pathways controlling Flg22- and chitosan-induced callose, we evaluated levels of PAMPinduced $\mathrm{H}_{2} \mathrm{O}_{2}$ and callose in mutants that are affected in ROSscavenging and ROS-producing enzymes. The cat2-1 mutant, which is impaired in a peroxisomal catalase (Bueso et al. 2007), allowed significantly enhanced levels of PAMP-induced $\mathrm{H}_{2} \mathrm{O}_{2}$ (Fig. 8A), which correlated with enhanced levels of callose deposition (Fig. 8B). This phenotype is consistent with a potentiating function of $\mathrm{H}_{2} \mathrm{O}_{2}$ in callose deposition, since the cat2-1 mutant is reduced in its ability to scavenge $\mathrm{H}_{2} \mathrm{O}_{2}$ (Bueso et al. 2007). In support of this, the rbohD mutant, carrying a TDNA knock-out mutation in the superoxide-generating NADPH oxidase gene RBOHD (Pogany et al. 2009), accumulated reduced levels of Flg22-induced $\mathrm{H}_{2} \mathrm{O}_{2}$ and failed to deposit enhanced levels of callose upon treatment with Flg22 (Fig. 8). Surprisingly, however, rbohD deposited wild-type levels of callose in response to chitosan (Fig. 8B), despite an obvious reduction in chitosan-induced $\mathrm{H}_{2} \mathrm{O}_{2}$ (Fig. 8A). Similar results were obtained in response to a fivefold lower dose of chitosan (0.002\%; Supplementary Fig. S2), suggesting that the intact callose response of $r b o h D$ to chitosan is not due to overstimulation of the defense response or phytotoxicity of chitosan.
Hence, chitosan-induced callose, unlike Flg22-induced callose, functions independently of RBOHD-dependent $\mathrm{H}_{2} \mathrm{O}_{2}$. The vtc1-1 mutant, which accumulates 10-fold lower levels of antioxidant ascorbic acid than wild-type plants (Conklin et al. 2000), also showed differential responsiveness to $\mathrm{Flg} 22$ and chitosan (Fig. 8B). As expected, vtc1-1 plants allowed dramatically enhanced levels of $\mathrm{H}_{2} \mathrm{O}_{2}$ accumulation under all conditions tested (Fig. 8A), which correlated with augmented levels of basal and chitosan-induced callose in comparison with wildtype plants (Fig. 8B). However, vtc1-1 failed to deposit increased levels of callose after treatment with Flg22 (Fig. 8B). Since ascorbic acid functions as a cofactor in myrosinasedependent break-down of glucosinolates (Burmeister et al. 2000), the inability of $v t c 1-1$ to deposit enhanced callose upon Flg22 treatment confirms the earlier finding that glucosinolate metabolites regulate Flg22-induced callose (Clay et al. 2009). Accordingly, basal and chitosan-induced callose is not controlled by glucosinolate-derived metabolites.

To clarify the role of glucosinolate metabolites in callose deposition, we tested the myrosinase mutant pen $2-2$, which is blocked in production of specific glucosinolate break-down products (Bednarek et al. 2009; Clay et al. 2009). Like the vtc1-1 mutant, pen2-2 failed to deposit enhanced callose in response to $\mathrm{Flg} 22$, whereas treatment of pen $2-2$ with 0.002 or $0.01 \%$ chitosan induced statistically significant enhancements in callose deposition (Fig. 8B). Hence, glucosinolate metabolites play a role in Flg22-induced callose but play no role in chitosaninduced callose deposition.

To examine the contribution of the callose synthase PMR4, we quantified levels of Flg22- and chitosan-induced callose in the pmr4-1 mutant (Nishimura et al. 2003). As expected, pmr4-1 deposited dramatically reduced levels of basal callose

\section{Flg22}
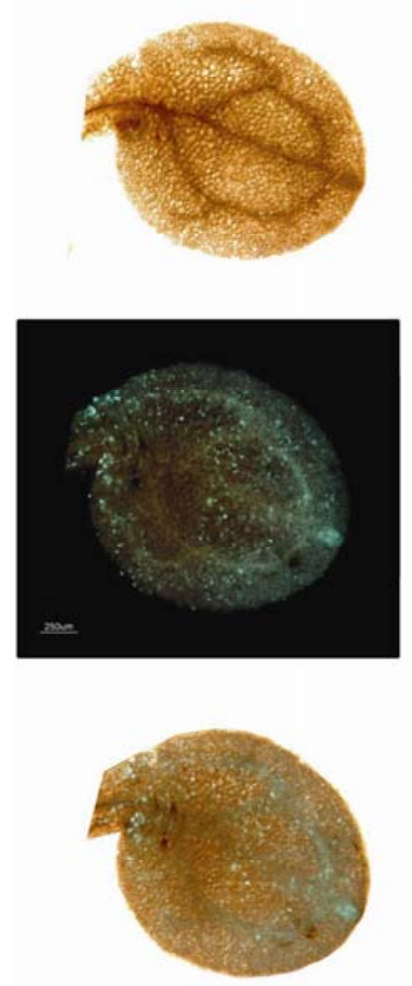
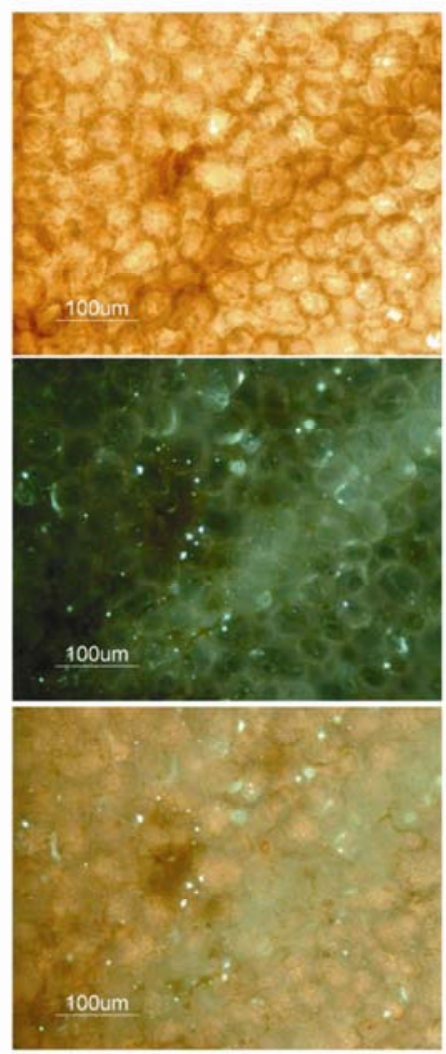

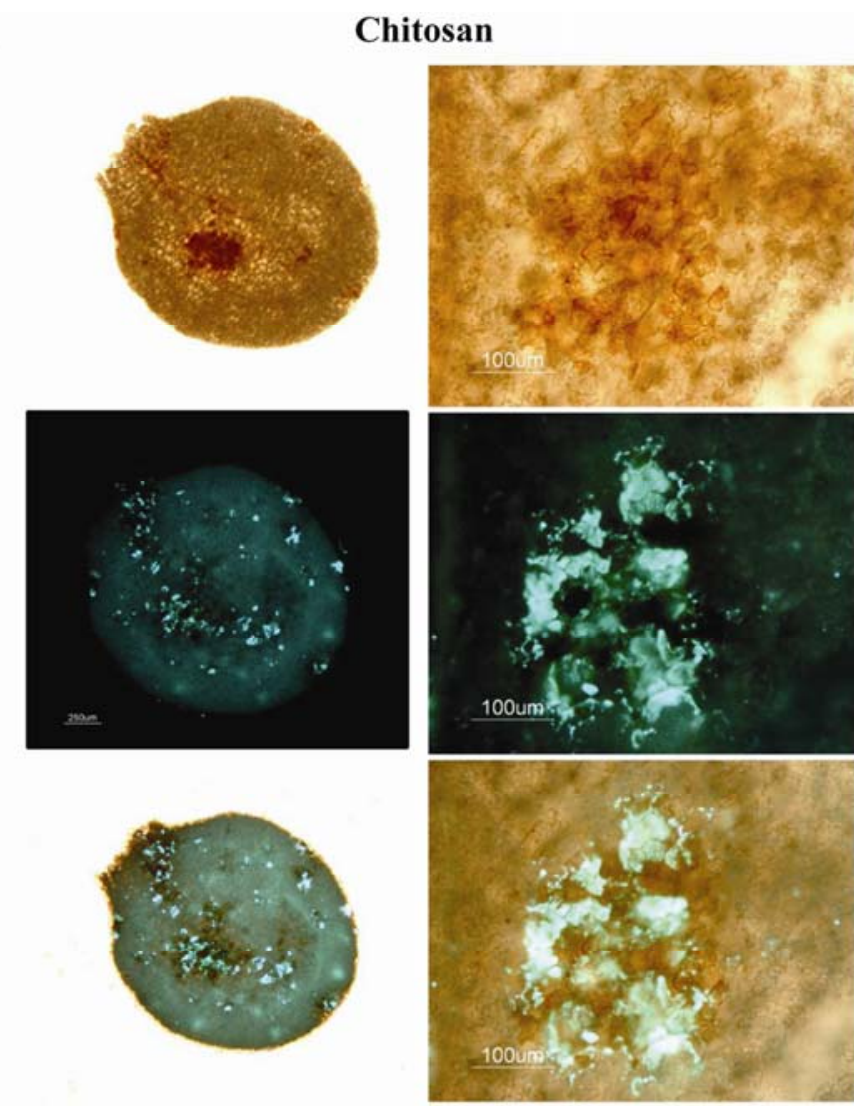

Fig. 6. Localization of $\mathrm{H}_{2} \mathrm{O}_{2}$ and callose at $24 \mathrm{~h}$ after treatment with $1 \mu \mathrm{M}$ Flg 22 or $0.01 \%$ chitosan. Photographs show double-stained cotyledons (3,3diaminobenzidine and aniline-blue) exposed to a combination of bright light and UV. Seedlings were grown under $150 \mu \mathrm{E} \mathrm{m}^{-2} \mathrm{~s}^{-1}$ light, $1 \%$ sucrose, without Gamborg vitamins. 
and failed to respond to Flg22 (Fig. 9). However, chitosan elicited a residual callose response in pmr4-1 plants, even though the absolute levels of chitosan-induced callose were reduced by $90 \%$ in comparison to the wild-type (Fig. 9). Thus, Flg22induced callose is entirely derived from PMR4, while approximately $10 \%$ of chitosan-induced callose comes from one or more other callose synthases than PMR4.

\section{DISCUSSION}

The primary objective of this study was to evaluate the robustness and reproducibility of a widely used model system in PTI plant research, i.e., PAMP-induced callose in cotyledons of hydroponically grown Arabidopsis seedlings. Although exogenous application of Flg22 or chitosan consistently boosted callose levels, overall callose production varied according to the growth conditions. This environmental variability affected both basal callose deposition in mock-treated plants and PAMP-induced callose in Flg22- and chitosan-treated plants. Hence, the environmental growth conditions do not exclusively act on the responsiveness to PAMPs but, rather, affect the plant's overall capacity to deposit callose (Figs. 2 and 3). Remarkably, pretreat-

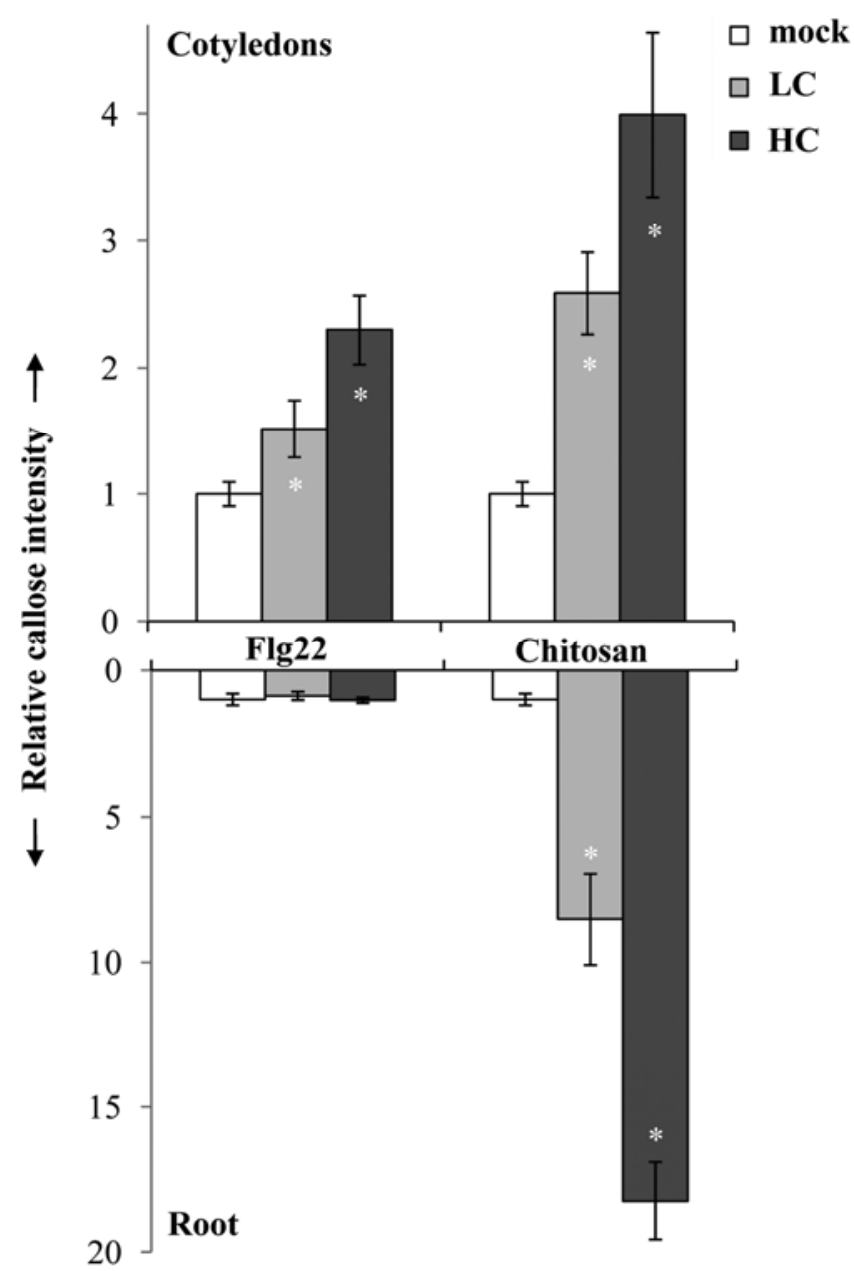

Fig. 7. Callose deposition in cotyledons and roots in response to Flg22 or chitosan. Data shown are average values ( \pm standard error of the mean; $n>$ 20) of relative callose intensities at $24 \mathrm{~h}$ after pathogen-associated molecular pattern (PAMP) treatment. Values were standardized to intensities in mock-treated tissues. Seedlings were treated with $5 \mu \mathrm{M}$ abscissic acid at $24 \mathrm{~h}$ prior to PAMP treatment. Asterisks indicate statistically significant changes in response to PAMP treatment (Student's $t$-test; $\alpha=0.05$ ). LC = low PAMP concentration, i.e., $0.2 \mu \mathrm{M}$ Flg22 or $0.002 \%$ chitosan; $\mathrm{HC}=$ high PAMP concentration, i.e., $1 \mu \mathrm{M}$ Flg22 or $0.01 \%$ chitosan. ment with the environmental response hormone ABA had opposite effects on callose production, depending on the environmental growth conditions (Fig. 4). These results not only provide an explanation for the controversial role of ABA in callose defense (Ton et al. 2009), but they also complicate the interpretation of callose deposition as a uniform defense marker of PTI signaling. In support of that conclusion, we furthermore found that the pathways controlling Flg22- and chitosan-induced callose differ in their requirement for various signal transduction components. Hence, the model system of PAMP-induced callose in hydroponically grown Arabidopsis involves regulation by more than one pathway, which differs according to the environmental conditions and the eliciting PAMP. This outcome warrants extra caution with generalizations regarding PTI signaling on the basis of this model system.

Antioxidant vitamins suppressed callose deposition, whereas light intensity stimulated callose deposition (Fig. 2). The accumulation of $\mathrm{H}_{2} \mathrm{O}_{2}$ displayed remarkably similar pat-


Fig. 8. Effect of mutations in homeostasis of reactive oxygen species (ROS) and biosynthesis of indolytic glucosinolates (IGS) on $\mathbf{A}, \mathrm{H}_{2} \mathrm{O}_{2}$ production and $\mathbf{B}$, callose deposition upon treatment with $1 \mu \mathrm{M}$ Flg22 or $0.01 \%$ chitosan. Data shown are average values ( \pm standard error of the mean; $n>15$ ) of relative staining intensities. Values were standardized to staining intensities in mock-treated wild-type seedlings (Col-0). Seedlings were treated with $5 \mu \mathrm{M}$ abscissic acid at $24 \mathrm{~h}$ prior to pathogen-associated molecular pattern (PAMP) treatment. Asterisks indicate statistically significant changes in response to PAMP treatment within each genotype (Student's $t$-test; $\alpha=0.05$ ). n.s. = no statistically significant difference between mock- and PAMP-treated seedlings. 
terns of variation at these growth conditions (Fig. 3), suggesting that the environmental variability in callose deposition is caused by fluctuations in ROS. In this context, the callose-promoting effects by exogenously applied ABA (Fig. 4; Table 2) can be explained by ABA-induced ROS (Ghassemian et al. 2008; Xing et al. 2008). Conversely, the observed suppression by sucrose (Fig. 2) can be explained by repression of photosynthesis activity and related ROS (Paul and Driscoll 1997; Sheen 1990). Two recent studies identified five PTI signaling components on the basis of a mutant screen in Elf18-induced repression of anthocyanins at high sucrose, demonstrating that the negative cross-talk between sucrose and PTI signaling acts in two directions ( $\mathrm{Lu}$ et al. 2009; Saijo et al. 2009). All five "PRIORITY IN SWEET LIFE" genes (PSL) isolated from this mutant screen encode components in endoplasmatic reticulumlocalized N-glycosylation, which regulates quality control and stable expression of the Elf18 receptor EFR. Interestingly however, the $p s l$ mutants were unaffected in stability and functioning of the Flg22 receptor FLS2 (Lu et al. 2009; Saijo et al. 2009), demonstrating that the involvement of N-glycosylation in PTI signaling is PAMP-specific (Haweker et al. 2010; Saijo 2010). In this study, we demonstrated a PAMP-specific contribution of signaling components further downstream in PTI signaling, such as AtRBOHD, glucosinolate metabolites, and even the callose synthase PMR4 (Figs. 8 and 9). Considering that single pathogen species produce multiple PAMP signals, we conclude that callose deposition in response to pathogen infection is regulated by multiple signaling pathways rather than one conserved downstream pathway.

The contrasting effects of ABA on callose regulation under different growth conditions point to a complex interplay between environmental signaling pathways. In our experiments, ABA repressed basal and PAMP-induced callose at low light intensity, high sucrose concentration and vitamins (Fig. 4), whereas all other conditions supported predominantly stimulatory effects by ABA (Fig. 4; Table 2). Previously, it was shown that ABA represses Flg22-induced callose in hydroponic Arabidopsis under nearly identical growth conditions (Clay et al. 2009), except for the concentration of sucrose in the growth medium (0.5\%) (Clay et al. 2009). This callose suppression by ABA was explained by a repressed activity of the ethyleneinducible transcription factor MYB51, which regulates the bio-

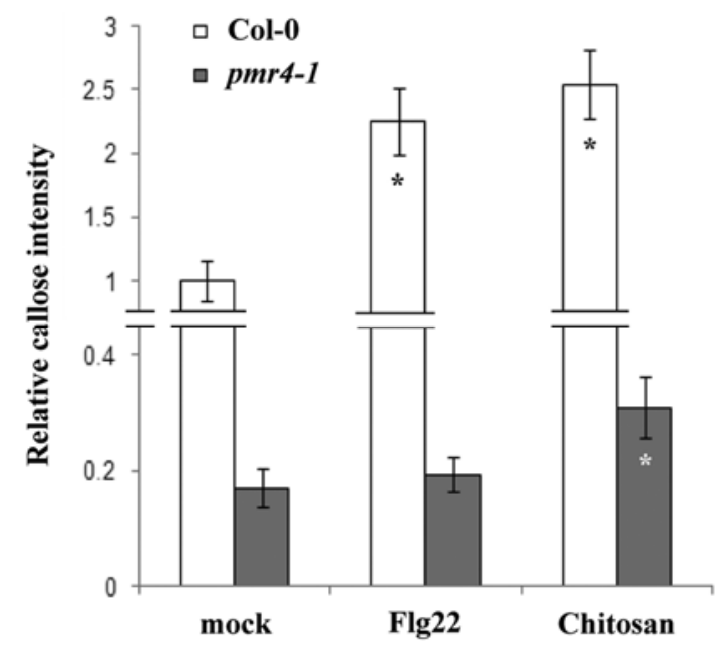

Fig. 9. Callose deposition in wild-type (Col-0) and pmr4-1 seedlings at 24 $\mathrm{h}$ after treatment with $1 \mu \mathrm{M}$ Flg22, or $0.01 \%$ chitosan. Asterisks indicate statistically significant changes in response to pathogen-associated molecular pattern (PAMP) treatment within each genotype (Student's $t$-test: $\alpha=0.05$ ). n.s. = no statistically significant difference between mock- and PAMPtreated seedlings. synthesis of indolic glucosinolates (Gigolashvili et al. 2007). However, such cross-talk mechanism does not explain why ABA stimulates callose under other growth conditions. Interestingly, our study demonstrated that growth conditions supporting $\mathrm{ABA}$-induced potentiation of callose allow for enhanced levels of $\mathrm{H}_{2} \mathrm{O}_{2}$ accumulation in the tissue (Figs. 3 and 4). Furthermore, exogenous application of ABA has been demonstrated to trigger $\mathrm{H}_{2} \mathrm{O}_{2}$ accumulation in Arabidopsis (Xing et al. 2008). We, therefore, propose that environmental growth conditions can boost ABA-induced ROS to a threshold that promotes callose, thereby masking or bypassing ABA-induced suppression of MYB51-dependent callose.

The analysis of Arabidopsis signaling mutants revealed that the cat2-1 mutant accumulates significantly enhanced levels of $\mathrm{H}_{2} \mathrm{O}_{2}$ and callose after treatment with Flg22 or chitosan (Fig. 8 ). Considering that cat $2-1$ is impaired in a peroxisomal catalase (Bueso et al. 2007), this mutant phenotype confirms a potentiating role of $\mathrm{H}_{2} \mathrm{O}_{2}$ in both Flg22- and chitosan-induced callose. We furthermore found that the rbohD mutant is blocked in Flg22-induced callose but not in chitosan-induced callose (Fig. 8B), whereas both Flg22- and chitosan-induced $\mathrm{H}_{2} \mathrm{O}_{2}$ were dramatically reduced in this mutant (Fig. 8A). Hence, chitosan-induced callose does not require $\mathrm{H}_{2} \mathrm{O}_{2}$ from the NADPH oxidase RBOHD. Furthermore, rbohD seedlings still showed a statistically significant increase in $\mathrm{H}_{2} \mathrm{O}_{2}$ after PAMP treatment, despite the obvious reduction in absolute $\mathrm{H}_{2} \mathrm{O}_{2}$ levels compared with wild-type plants. This demonstrates that PAMP-induced $\mathrm{H}_{2} \mathrm{O}_{2}$ is only partially derived from RBOHD. Consequently, we propose that Flg22-induced callose, like OG-induced callose (Galletti et al. 2008), is controlled by RBOHD-dependent $\mathrm{H}_{2} \mathrm{O}_{2}$, whereas chitosan-induced callose is controlled by $\mathrm{RBOHD}$-independent $\mathrm{H}_{2} \mathrm{O}_{2}$. Additional evidence for differential regulation of Flg22- and chitosan-induced callose comes from the behavior of the pen2-2 and vtcl-1 mutants. Both mutants were blocked in Flg22-induced callose but were unaffected in chitosan-induced callose (Fig. 8B). Given the role of PEN2 and VTC1 in the hydrolysis of glucosinolates (Bednarek et al. 2009; Burmeister et al. 2000; Clay et al. 2009), we support the conclusion that Flg22-induced callose is regulated by glucosinolate-derived metabolites. However, these metabolites are apparently not involved in the regulation of chitosan-induced callose.

Chitosan has long been known for its defense-eliciting capacities in plants, even though the nature and intensity of the chitosan-induced plant defense response differs according to its physiochemical characteristics, such as degree of de-acytelation, viscosity, and molecular weight (Iritri and Faoro 2009). In this study, we have used low-viscous chitosan with a molecular weight of approximately $150 \mathrm{kDa}$ and a 95 to $98 \%$ degree of acetylation (Hombach and Bernkop-Schnürch 2009). The only mutation that significantly reduced chitosan-induced callose was the pmr4-1 mutation (Fig. 9). Conversely, mutations affecting the plant's ROS-scavenging ability, such as cat2-1 and vtc1-1, allowed for augmented levels of chitosaninduced callose (Fig. 8). Furthermore, both Flg22- and chitosan-induced callose were consistently higher under environmental growth conditions that allowed for higher levels of ROS accumulation (Figs. 2 and 3). Hence, despite the specific differences between the pathways controlling Flg22- and chitosan-induced callose, ROS seem to have a potentiating effect on callose production in general.

The Flg22 response of Arabidopsis has emerged as a widely used model system to study PTI signaling. Recognition of Flg22 triggers a rapid mitogen-activated protein kinase (MAPK) cascade involving the defense regulatory kinases MAPK3 and MAPK6 (Asai et al. 2002; Suarez-Rodriguez et al. 2007), which can be suppressed by virulence-promoting 
pathogen effectors (He et al. 2006; Zhang et al. 2007). This MPK3- and MPK6-dependent MAPK cascade activates downstream WRKY transcription factors that promote transcription of early-acting defense genes (Asai et al. 2002; Navarro et al. 2004). In addition, this MAPK cascade stimulates generation of RBOHD-dependent ROS, which subsequently promote deposition of PMR4-dependent callose (He et al. 2006; Zhang et al. 2007). The recent discovery that glucosinolate metabolites regulate Flg22-induced callose adds a novel layer to signaling pathways controlling this PTI response (Clay et al. 2009). Given the toxic nature of glucosinolate break-down products (Halkier and Gershenzon 2006), their function in callose deposition may be explained as part of a cellular detoxification response, which mediates secretion of these defense metabolites into the apoplast, in which they are captured in callose-containing papillae. Accordingly, glucosinolate metabolites act at relatively late stages of the Flg22-induced pathway. In support of this, we found that $v t c 1-1$ and pen2-2 are not reduced in Flg22-induced $\mathrm{H}_{2} \mathrm{O}_{2}$, suggesting that glucosinolate metabolites act downstream of RBOHD-generated $\mathrm{H}_{2} \mathrm{O}_{2}$ in the regulation of Flg22-induced callose.

Unlike other studies, our experiments revealed relatively high basal levels of callose in the mock treatments. Apart from differences in growth conditions, this discrepancy could be related to a difference in staining technique. Whereas our experiments used ethanol for the destaining of green tissues, other studies commonly use ethanol followed by treatment with $10 \% \mathrm{NaOH}$ for this purpose (Clay et al. 2009; Millet et al. 2010). It is possible that incubation in such a strongly alkaline solution removes or eradicates part of the callose that is present at the cell wall, thereby lowering the detection limit of callose and giving the impression that cotyledons from mock-treated plants contain no callose. Another surprising outcome was the lack of Flg22induced callose in roots, which contradicts a recent report by Millet and associates (2010), who demonstrated that Flg22induced callose in Arabidopsis roots depends on a similar pathway as Flg22-induced callose in cotyledons (Clay et al. 2009). It seems difficult to envisage that our staining method fails to detect Flg22-induced callose in the roots while is suitable for detection of basal and chitosan-induced callose in the roots. It is, therefore, more plausible that this discrepancy originates from differences in growth conditions. Whereas Millet and associates (2010) cultivated seedlings in Murashige Skoog (MS) medium with vitamins at a light intensity of $100 \mu \mathrm{E} \mathrm{m}^{-2} \mathrm{~s}^{-1}$, we cultivated the seedlings in medium without vitamins at $150 \mu \mathrm{E} \mathrm{m}^{-2} \mathrm{~s}^{-1}$ of light. Since higher levels of light and lack of vitamins allow for significantly higher levels of basal ROS and callose accumulation (Figs. 2B and 3), we propose that Flg22-induced callose in roots was masked by relatively high basal levels of callose deposition under our experimental conditions.

In summary, our study uncovered an unexpectedly large degree of environmental variation in callose deposition of hydroponically grown Arabidopsis. It is of concern that this model system is widely used to study PTI signaling and seems to be designed to minimise experimental variation. It can, therefore, be expected that fluctuations in environmental growth conditions have even bigger impacts on PTI signaling during more complex interactions, such as those between soil-grown plants and pathogenic microbes or plant-beneficial microbes or both. This could also explain the previously reported controversy about the involvement of plant hormones in plant-microbe interactions (Beckers and Spoel 2006; Robert-Seilaniantz et al. 2007; Ton et al. 2009) as well as inconsistencies in complex plant-microbe assays. Above all, our study warrants the use of extra caution with generalizations regarding plant innate immunity on the basis of callose deposition in hydroponically grown Arabidopsis seedlings.

\section{MATERIALS AND METHODS}

Plant material, growth conditions, and chemical treatments.

Seeds of Arabidopsis thaliana accession Col-0 and mutants in this background (pmr4-1 [Nishimura et al. 2003], vtc1-1 [Conklin et al. 2000], cat2-1 [Bueso et al. 2007], pen2-2 [Lipka et al. 2005], and rbohD [Pogany et al. 2009]) were vaporphase sterilized for 4 to $6 \mathrm{~h}$ (S. Clough and A. Bent, personal communication). Approximately 15 seeds per well were planted in sterile 12-well plates, each containing $1 \mathrm{ml}$ of filtersterilized basal MS medium with or without Gamborg vitamins (Sigma) (containing $100 \mu \mathrm{g}$ of myo-inositol per liter, 1 $\mu \mathrm{g}$ of nicotinic acid per liter, $1 \mu \mathrm{g}$ of pyridoxine hydrochloride per liter, and $10 \mu \mathrm{g}$ of thiamine hydrochloride per liter) with varying concentrations of sucrose $(0,1,2.5$, and $5 \%)$. All growth media were supplemented with $0.5 \%$ morpholineethanesulfonic acid hydrate (final $\mathrm{pH}=5.7$ to 5.8). Plates were kept in the dark at $4^{\circ} \mathrm{C}$ for 1 to 2 days before being transferred to controlled growth cabinets. Seedlings were cultivated under standard growth conditions (16-h-day and 8-h-night cycle; $20^{\circ} \mathrm{C}$ and $17^{\circ} \mathrm{C}$, respectively) at two different light intensities (75 and $150 \mu \mathrm{E} \mathrm{m}^{-2} \mathrm{~s}^{-1}$ ). At 7 days of growth, MS medium was replaced with fresh medium. ABA was applied at day 8 to a final concentration to 5 or $50 \mu \mathrm{M}$. At day 9 , seedlings were challenged with $1 \mu \mathrm{M}$ Flg22 (applied as $10 \mu \mathrm{l}$ of $100 \mu \mathrm{M}$ Flg22 solution) (GenScript, Piscataway, NJ, U.S.A.) or $0.01 \%$ (wt/vol) low-viscous chitosan (Fluka, Milwaukee, WI, U.S.A.) (applied as $10 \mu \mathrm{l}$ of $1 \%$ chitosan (vol/wt) solution in $1 \%$ acetic acid), which has a molecular weight of approximately $150 \mathrm{kDa}$ and a 95 to $99.8 \%$ degree of acetylation (Hombach and Bernkop-Schnürch 2009). These PAMP concentrations were based on previously reported dose-response experiments (Flg22, Gomez-Gomez et al. 1999b; chitosan, Iriti et al. 2006), as well as the consistency in callose responses between independent experiments (data not shown). Mock treatments were performed by the addition of $10 \mu \mathrm{l}$ of water to the growth medium. Addition of $10 \mu \mathrm{l}$ of $1 \%$ acetic acid did not change the $\mathrm{pH}$ nor influence callose deposition in mock- or Flg22-treated plants (data not shown). Experiments to examine callose deposition under different growth and ABA conditions were performed at three different laboratories, at Rothamsted Research, Harpenden, U.K., at the University of Jaume I of Castellón, Spain, and at the University of Neuchâtel, Switzerland.

\section{Aniline blue staining, microscopy analysis, and callose quantification.}

Seedlings were collected, destained in $95 \% \mathrm{EtOH}$ and stained with aniline-blue as described previously, with some modification (Ton et al. 2005). Briefly, seedlings were incubated for at least $24 \mathrm{~h}$ in 95 to $100 \%$ ethanol until all tissues were transparent, were washed in $0.07 \mathrm{M}$ phosphate buffer $(\mathrm{pH}$ $=9$ ), and were incubated for 1 to $2 \mathrm{~h}$ in $0.07 \mathrm{M}$ phosphate buffer containing $0.01 \%$ aniline-blue (Sigma, St. Louis), prior to microscopic analysis. Observations were performed with an epifluorescence microscope with UV filter (BP 340 to $380 \mathrm{~nm}$, LP $425 \mathrm{~nm}$ ). Callose was quantified from digital photographs by the number of white pixels (callose intensity) or the number of depositions relative to the total number of pixels covering plant material, using Photoshop CS2 software. Contrast settings of the photographs were adjusted to obtain an optimal separation of the callose signal from the background signal (Supplementary Fig. S3). Callose was selected automatically, using the "Color Range" tool. In cases in which the contrast settings resulted in significant loss of callose signal due to high autofluorescence signals from the vasculature, callose was selected manually, using the "Magic Wand" tool of Photoshop $\mathrm{CS} 3$. The accuracy of the resulting callose selection was visu- 
ally verified before proceeding. Callose-corresponding pixels and numbers of depositions were recorded as the area covered by the total number of selected pixels and the number of measurements, respectively, using the "Record Measurements" tool of Photoshop CS3. Average callose measurements were based on at least 20 photographs from different seedlings and were analyzed for statistical differences by Student's $t$-tests or analysis of variance following by Fisher's least significant differences tests $(n=20$ to $40 ; \alpha=0.05)$.

DAB staining, microscopy analysis, and $\mathrm{H}_{2} \mathrm{O}_{2}$ quantification.

Seedlings were stained in $1 \mathrm{mg}$ of DAB per milliliter at $\mathrm{pH}<$ 3 for $24 \mathrm{~h}$ in the dark and were subsequently destained in chloral-hydrate, as described previously (Thordal-Christensen et al. 1997). DAB staining intensities were quantified from digital photographs (Nikon Eclipse 11000, Tokyo) by the number of dark-brown DAB pixels relative to total pixels corresponding to plant material, using Photoshop CS3. Analysis for statistical differences were performed as described for the callose quantifications. For double staining of $\mathrm{H}_{2} \mathrm{O}_{2}$ and callose, plant material was stained with $\mathrm{DAB}$ as described above but was destained in 95\% ethanol instead of chloral-hydrate. Subsequently, samples were stained with aniline-blue, as described above.

\section{ACKNOWLEDGMENTS}

We thank F. Mauch for helpful comments and suggestions to earlier versions of this manuscript. This research was supported by a Leonardo Da Vinci grant to E. Luna and a BBSRC Institute Career Path Fellowship (number BB/E023959/1) to J. Ton. We thank the Swiss National Foundation for supporting B. Mauch-Mani (grant 31003A-120197) and the Plan de Promoción Bancaja-UJI P1.1A2007-07 and the Generalitat Valenciana GV/2007/099 for funding V. Flors. We are grateful to P. García for her support (AGL-2007-66282-C02-02).

\section{LITERATURE CITED}

Adams-Phillips, L., Briggs, A. G., and Bent, A. F. 2010. Disruption of poly(ADP-ribosyl)ation mechanisms alters responses of Arabidopsis to biotic stress. Plant Physiol. 152:267-280.

Asai, T., Tena, G., Plotnikova, J., Willmann, M. R., Chiu, W. L., GomezGomez, L., Boller, T., Ausubel, F. M., and Sheen, J. 2002. MAP kinase signalling cascade in Arabidopsis innate immunity. Nature 415:977983.

Asselbergh, B., De Vleesschauwer, D., and Hofte, M. 2008. Global switches and fine-tuning-ABA modulates plant pathogen defense. Mol. Plant-Microbe Interact. 21:709-719.

Beckers, G. J., and Spoel, S. H. 2006. Fine-tuning plant defence signalling: salicylate versus jasmonate. Plant Biol. (Stuttg) 8:1-10.

Bednarek, P., Pislewska-Bednarek, M., Svatos, A., Schneider, B., Doubsky, J., Mansurova, M., Humphry, M., Consonni, C., Panstruga, R., SanchezVallet, A., Molina, A., and Schulze-Lefert, P. 2009. A glucosinolate metabolism pathway in living plant cells mediates broad-spectrum antifungal defense. Science 323:101-106.

Boller, T., and Felix, G. 2009. A renaissance of elicitors: Perception of microbe-associated molecular patterns and danger signals by pattern-recognition receptors. Annu. Rev. Plant Biol. 60:379-406.

Brown, I., Trethowan, J., Kerry, M., Mansfield, J., and Bolwell, G. P. 1998. Localization of components of the oxidative cross-linking of glycoproteins and of callose synthesis in papillae formed during the interaction between non-pathogenic strains of Xanthomonas campestris and French bean mesophyll cells. Plant J. 15:333-343.

Bueso, E., Alejandro, S., Carbonell, P., Perez-Amador, M. A., Fayos, J., Bellés, J. M., Rodriguez, P. L., and Serrano, R. 2007. The lithium tolerance of the Arabidopsis cat 2 mutant reveals a cross-talk between oxidative stress and ethylene. Plant J. 52:1052-1065.

Burmeister, W. P., Cottaz, S., Rollin, P., Vasella, A., and Henrissat, B. 2000. High resolution X-ray crystallography shows that ascorbate is a cofactor for myrosinase and substitutes for the function of the catalytic base. J. Biol. Chem. 275:39385-39393.

Clay, N. K., Adio, A. M., Denoux, C., Jander, G., and Ausubel, F. M. 2009. Glucosinolate metabolites required for an Arabidopsis innate immune response. Science 323:95-101.

Conklin, P. L., Saracco, S. A., Norris, S. R., and Last, R. L. 2000. Identifi- cation of ascorbic acid-deficient Arabidopsis thaliana mutants. Genetics 154:847-856.

de Torres-Zabala, M., Truman, W., Bennett, M. H., Lafforgue, G., Mansfield, J. W., Rodriguez Egea, P., Bogre, L., and Grant, M. 2007. Pseudomonas syringae pv. tomato hijacks the Arabidopsis abscisic acid signalling pathway to cause disease. EMBO (Eur. Mol. Biol. Organ.) J. 26:1434-1443.

Dunning, F. M., Sun, W., Jansen, K. L., Helft, L., and Bent, A. F. 2007. Identification and mutational analysis of Arabidopsis FLS2 leucine-rich repeat domain residues that contribute to flagellin perception. Plant Cell 19:3297-3313.

Flors, V., Ton, J., Jakab, G., and Mauch-Mani, B. 2005. Abscisic acid and callose: Team players in defence against pathogens? J. Phytopathol. 153:377-383

Fu, Z. Q., Guo, M., Jeong, B. R., Tian, F., Elthon, T. E., Cerny, R. L., Staiger, D., and Alfano, J. R. 2007. A type III effector ADP-ribosylates RNA-binding proteins and quells plant immunity. Nature 447:284-288.

Galletti, R., Denoux, C., Gambetta, S., Dewdney, J., Ausubel, F. M., De Lorenzo, G., and Ferrari, S. 2008. The AtrbohD-mediated oxidative burst elicited by oligogalacturonides in Arabidopsis is dispensable for the activation of defense responses effective against Botrytis cinerea. Plant Physiol. 148:1695-1706.

Gamborg, O. L., Miller, R. A., and Ojima, K. 1968. Nutrient requirements of suspension cultures of soybean root cells. Exp. Cell Res. 50:151-158.

Ghassemian, M., Lutes, J., Chang, H. S., Lange, I., Chen, W., Zhu, T., Wang, X., and Lange, B. M. 2008. Abscisic acid-induced modulation of metabolic and redox control pathways in Arabidopsis thaliana. Phytochemistry 69:2899-2911.

Gigolashvili, T., Berger, B., Mock, H. P., Muller, C., Weisshaar, B., and Flugge, U. I. 2007. The transcription factor HIG1/MYB51 regulates indolic glucosinolate biosynthesis in Arabidopsis thaliana. Plant J. 50:886-901.

Gomez-Gomez, L., and Boller, T. 2000. FLS2: An LRR receptor-like kinase involved in the perception of the bacterial elicitor flagellin in Arabidopsis. Mol. Cell 5:1003-1012.

Gomez-Gomez, L., Felix, G., and Boller, T. 1999a. A single locus determines sensitivity to bacterial flagellin in Arabidopsis thaliana. Plant J. 18:277-284.

Gomez-Gomez, L., Felix, G., and Boller, T. 1999b. A single locus determines sensitivity to bacterial flagellin in Arabidopsis thaliana. Plant J. 18:277-284.

Halkier, B. A., and Gershenzon, J. 2006. Biology and biochemistry of glucosinolates. Annu. Rev. Plant Biol. 57:303-333.

Haweker, H., Rips, S., Koiwa, H., Salomon, S., Saijo, Y., Chinchilla, D., Robatzek, S., and von Schaewen, A. 2010. Pattern recognition receptors require $\mathrm{N}$-glycosylation to mediate plant immunity. J. Biol. Chem. 285:4629-4636.

He, P., Shan, L., Lin, N.-C., Martin, G. B., Kemmerling, B., Nürnberger, T., and Sheen, J. 2006. Specific bacterial suppressors of MAMP signaling upstream of MAPKKK in Arabidopsis innate immunity. Cell 125:563-575.

Hombach, J., and Bernkop-Schnürch, A. 2009. Chitosan solutions and particles: Evaluation of their permeation enhancing potential on MDCK cells used as blood brain barrier model. Int. J. Pharm. 376:104-109.

Iriti, M., Sironi, M., Gomarasca, S., Casazza, A. P., Soave, C., and Faoro, F. 2006. Cell death-mediated antiviral effect of chitosan in tobacco. Plant Physiol. Biochem. 44:893-900.

Iritri, M., and Faoro, F. 2009. Chitosan as a MAMP, searching for a PRR. Plant, Signal. Behav. 4:66-68.

Jeworutzki, E., Roelfsema, M. R., Anschutz, U., Krol, E., Elzenga, J. T., Felix, G., Boller, T., Hedrich, R., and Becker, D. 2010. Early signaling through the Arabidopsis pattern recognition receptors FLS2 and EFR involves $\mathrm{Ca}(2+)$-associated opening of plasma membrane anion channels. Plant J. 62: 367-378.

Kohler, A., Schwindling, S., and Conrath, U. 2002. Benzothiadiazoleinduced priming for potentiated responses to pathogen infection, wounding, and infiltration of water into leaves requires the NPR1/NIM1 gene in Arabidopsis. Plant Physiol. 128:1046-1056.

Kunze, G., Zipfel, C., Robatzek, S., Niehaus, K., Boller, T., and Felix, G. 2004. The $\mathrm{N}$ terminus of bacterial elongation factor $\mathrm{Tu}$ elicits innate immunity in Arabidopsis plants. Plant Cell 16:3496-3507.

Li, Y., Zhang, Q., Zhang, J., Wu, L., Qi, Y., and Zhou, J.-M. 2010. Identification of microRNAs involved in pathogen-associated molecular pattern-triggered plant innate immunity. Plant Physiol. 152:2222-2231.

Lipka, V., Dittgen, J., Bednarek, P., Bhat, R., Wiermer, M., Stein, M., Landtag, J., Brandt, W., Rosahl, S., Scheel, D., Llorente, F., Molina, A., Parker, J., Somerville, S., and Schulze-Lefert, P. 2005. Pre- and postinvasion defenses both contribute to nonhost resistance in Arabidopsis. Science 310:1180-1183.

Lu, X., Tintor, N., Mentzel, T., Kombrink, E., Boller, T., Robatzek, S., 
Schulze-Lefert, P., and Saijo, Y. 2009. Uncoupling of sustained MAMP receptor signaling from early outputs in an Arabidopsis endoplasmic reticulum glucosidase II allele. Proc. Natl. Acad. Sci. U.S.A. 106:22522-22527.

Mauch-Mani, B., and Mauch, F. 2005. The role of abscisic acid in plantpathogen interactions. Curr. Opin. Plant Biol. 8:409-414.

Millet, Y. A., Danna, C. H., Clay, N. K., Songnuan, W., Simon, M. D., Werck-Reichhart, D., and Ausubel, F. M. 2010. Innate immune responses activated in Arabidopsis roots by microbe-associated molecular patterns. Plant Cell 22:973-990.

Navarro, L., Zipfel, C., Rowland, O., Keller, I., Robatzek, S., Boller, T., and Jones, J. D. 2004. The transcriptional innate immune response to flg22. Interplay and overlap with Avr gene-dependent defense responses and bacterial pathogenesis. Plant Physiol. 135:1113-1128.

Nicaise, V., Roux, M., and Zipfel, C. 2009. Recent advances in PAMPtriggered immunity against bacteria: Pattern recognition receptors watch over and raise the alarm. Plant Physiol. 150:1638-1647.

Nishimura, M. T., Stein, M., Hou, B. H., Vogel, J. P., Edwards, H., and Somerville, S. C. 2003. Loss of a callose synthase results in salicylic acid-dependent disease resistance. Science 301:969-972.

Paul, M. J., and Driscoll, S. P. 1997. Sugar repression of photosynthesis: The role of carbohydrates in signalling nitrogen deficiency through source:sink imbalance. Plant Cell Environ. 20:110-116.

Pogany, M., von Rad, U., Grun, S., Dongo, A., Pintye, A., Simoneau, P., Bahnweg, G., Kiss, L., Barna, B., and Durner, J. 2009. Dual roles of reactive oxygen species and NADPH oxidase RBOHD in an Arabidopsis-Alternaria pathosystem. Plant Physiol. 151:1459-1475.

Ridley, B. L., O'Neill, M. A., and Mohnen, D. 2001. Pectins: Structure, biosynthesis, and oligogalacturonide-related signaling. Phytochemistry 57:929-967.

Robatzek, S., Chinchilla, D., and Boller, T. 2006. Ligand-induced endocytosis of the pattern recognition receptor FLS2 in Arabidopsis. Genes Dev. 20:537-542.

Robert-Seilaniantz, A., Navarro, L., Bari, R., and Jones, J. D. 2007. Pathological hormone imbalances. Curr Opin Plant Biol 10:372-9.

Saijo, Y. 2010. ER quality control of immune receptors and regulators in plants. Cell Microbiol. 12: 716-724.

Saijo, Y., Tintor, N., Lu, X., Rauf, P., Pajerowska-Mukhtar, K., Haweker, H., Dong, X., Robatzek, S., and Schulze-Lefert, P. 2009. Receptor quality control in the endoplasmic reticulum for plant innate immunity. EMBO (Eur. Mol. Biol. Organ.) J. 28:3439-3449.
Sheen, J. 1990. Metabolic repression of transcription in higher plants. Plant Cell 2:1027-1038.

Suarez-Rodriguez, M. C., Adams-Phillips, L., Liu, Y., Wang, H., Su, S.-H., Jester, P. J., Zhang, S., Bent, A. F., and Krysan, P. J. 2007. MEKK1 Is Required for flg22-induced MPK4 activation in Arabidopsis plants. Plant Physiol. 143:661-669.

Thordal-Christensen, H., Zhang, Z., Wei, Y., and Collinge, D. B. 1997. Subcellular localization of $\mathrm{H}_{2} \mathrm{O}_{2}$ in plants. $\mathrm{H}_{2} \mathrm{O}_{2}$ accumulation in papillae and hypersensitive response during the barley-powdery mildew interaction. Plant J. 11:1187-1194.

Ton, J., Flors, V., and Mauch-Mani, B. 2009. The multifaceted role of ABA in disease resistance. Trends Plant Sci. 14:310-317.

Ton, J., Jakab, G., Toquin, V., Flors, V., Iavicoli, A., Maeder, M. N., Metraux, J. P., and Mauch-Mani, B. 2005. Dissecting the beta-aminobutyric acid-induced priming phenomenon in Arabidopsis. Plant Cell 17:987-999.

Ton, J., and Mauch-Mani, B. 2004. Beta-amino-butyric acid-induced resistance against necrotrophic pathogens is based on ABA-dependent priming for callose. Plant J. 38:119-130.

Wang, L., Tsuda, K., Sato, M., Cohen, J. D., Katagiri, F., and Glazebrook, J. 2009. Arabidopsis $\mathrm{CaM}$ binding protein CBP60g contributes to MAMP-induced SA accumulation and is involved in disease resistance against Pseudomonas syringae. PLoS Pathog 5:e1000301. Published online.

Xing, Y., Jia, W., and Zhang, J. 2008. AtMKK1 mediates ABA-induced CAT1 expression and $\mathrm{H}_{2} \mathrm{O}_{2}$ production via AtMPK6-coupled signaling in Arabidopsis. Plant J. 54:440-451.

Yakushiji, S., Ishiga, Y., Inagaki, Y., Toyoda, K., Shiraishi, T., and Ichinose, Y. 2009. Bacterial DNA activates immunity in Arabidopsis thaliana. J. Gen. Plant Pathol. 75:227-234.

You, M. K., Shin, H. Y., Kim, Y. J., Ok, S. H., Cho, S. K., Jeung, J. U., Yoo, S. D., Kim, J. K., and Shin, J. S. 2010. Novel bifunctional nucleases, OmBBD and AtBBD1, are involved in abscisic acid-mediated callose deposition in Arabidopsis. Plant Physiol. 152:1015-1029.

Zhang, J., Shao, F., Li, Y., Cui, H., Chen, L., Li, H., Zou, Y., Long, C., Lan, L., Chai, J., Chen, S., Tang, X., and Zhou, J. M. 2007. A Pseudomonas syringae effector inactivates MAPKs to suppress PAMP-induced immunity in plants. Cell Host Microbe 1:175-185.

Zimmerli, L., Jakab, G., Métraux, J.-P., and Mauch-Mani, B. 2000. Potentiation of pathogen-specific defense mechanisms in Arabidopsis by $\beta$ aminobutyric acid. Proc. Natl. Acad. Sci. U.S.A. 97:12920-12925. 